\title{
PROFILE OF ASPHYXIATED BABIES AT NEONATAL INTENSIVE CARE UNIT IN A TERTIARY CARE HOSPITAL IN NORTH EASTERN INDIA
}

\author{
Ananta Kumar Nath1, Dipangkar Hazarika² \\ ${ }^{1}$ Registrar, Department of Paediatrics, Jorhat Medical College and Hospital. \\ ${ }^{2}$ Assistant Professor, Department of Paediatrics, Jorhat Medical College and Hospital.
}

\section{ABSTRACT}

\section{BACKGROUND}

Birth asphyxia is one of the major causes of neonatal mortality as well as morbidity in India, but it studied that the causes which lead to asphyxia are usually preventable. Many metabolic as well as other sequential changes occurs in the body as a result of birth asphyxia which further lead to major long-term sequelae like cerebral palsy, mental retardation and seizure disorder.

\section{AIM}

To identify antepartum, intrapartum and postnatal risk factors for neonatal mortality due to birth asphyxia and to assess the clinico-biochemical status and outcome in the early neonatal period of babies who were asphyxiated at birth.

\section{DESIGN}

Cohort study.

\section{SETTING}

Neonatal Intensive Care Unit, Gauhati Medical College and Hospital.

\section{METHODS}

After clearance from the Hospital Ethical Committee, all severely asphyxiated babies at birth, admitted to neonatal unit from August 2009 to July 2010 were included in the study. A specially designed questionnaire was used to assess the role of maternal factors and neonatal presentation of birth asphyxia. Antenatal and intrapartum factors like maternal anaemia, Pregnancy Induced Hypertension (PIH), eclampsia, antenatal visits, Meconium Stained Amniotic Fluid (MSAF) were recorded. Asphyxiated babies were observed for stages of Hypoxic Ischaemic Encephalopathy (HIE), reflexes and any end organ involvement. Investigations were done for blood counts, electrolytes, USG, etc.

\section{RESULTS}

Among 150 babies, we found significant association between birth asphyxia and factors like poor antenatal check-up (48\%), MSAF (38.7\%), maternal anaemia (78\%), PIH (20.7\%), eclampsia (15.3\%), prolonged labour (28\%), ante partum foetal distress (14.7\%); $24 \%$ cases were in HIE stage I, $32 \%$ in stage II and $44 \%$ in stage III. Multiorgan involvement seen with renal (9.3\%), haematological (3.3\%) abnormalities. During management $54.6 \%$ needed inotropes $(54.6 \%)$ for circulatory support, $60 \%$ cases needed anticonvulsant and mortality rate was (48\%).

\section{CONCLUSION}

There were lots of potentially preventable factors associated with birth asphyxia, which can be prevented if there is proper antenatal care including prevention of anaemia and pregnancy induced complications and proper management during early neonatal period.

\section{KEYWORD}

Birth Asphyxia, Hypoxic Ischaemic Encephalopathy, Risk Factors, PIH.

HOW TO CITE THIS ARTICLE: Nath AK, Hazarika D. Profile of asphyxiated babies at neonatal intensive care unit in a tertiary care hospital in north eastern India. J. Evolution Med. Dent. Sci. 2016;5(42):2607-2610, DOI: 10.14260/jemds/2016/609

\section{INTRODUCTION}

Despite major advances in the field of foetal monitoring technology and neonatal medicine, birth asphyxia which is usually the most important cause of preventable neonatal cerebral injury, remains a serious condition that causes

Financial or Other, Competing Interest: None.

Submission 05-04-2016, Peer Review 07-05-2016,

Acceptance 12-05-2016, Published 25-05-2016.

Corresponding Author:

Dr. Ananta Kumar Nath,

Registrar, Department of Paediatrics,

Jorhat Medical College and Hospital,

Jail Road, Jorhat-785001, Assam. India.

E-mail: dreamyou143@gmail.com

DOI: $10.14260 /$ jemds/2016/609 significant mortality and long-term neurologic morbidity. ${ }^{1}$ Sequential changes of pathologic, biochemical and metabolic pathway is the main cause of multisystemic involvement of birth asphyxia which subsequently affects near about all organ systems like central nervous system, cardiovascular system, pulmonary, renal, adrenal, gastrointestinal tract, skin, haematopoietic system, etc. Among them neurological complications are the most dangerous as the child may not recover fully and there is every chances of developing longterm sequelae like cerebral palsy, mental retardation and in some cases incapacitating disability. ${ }^{1,2}$ This creates a great burden for the family as well as for the society.

Birth asphyxia is classified depending upon the APGAR scoring done by the obstetricians and paediatricians in delivery room at one minute and then at fifth minute after 
delivery. Perinatal asphyxia was graded as non-severe (1-minute Apgar score $\leq 6$ and/or umbilical artery $\mathrm{pH}<7.20$ with abnormal foetal heart rate patterns and/or meconiumstained amniotic fluid and the need for immediate neonatal resuscitation) and severe (1-minute Apgar score $\leq 3$ and umbilical artery $\mathrm{pH}<7.10){ }^{3}$

According to World Health Organization estimates in the developing countries, $3 \%$ of all infants (3.6 millions) suffer from moderate-to-severe birth asphyxia, of which $23 \%$ $(840,000)$ die annually and approximately the equal number develop serious sequelae. ${ }^{4}$ As prevention is more important than treatment, so in a developing country like India, the need for risk assessment of birth asphyxia is much more important so that preventive measures can be taken during antenatal and intrapartum period.

Globally, each year about 4 million new-born die before they are 4 weeks' old and half of them die in their first 24 hours. ${ }^{5}$ In India neonatal mortality contributes to $70 \%$ of infant mortality. ${ }^{6}$ The causes of neonatal death in India are low birth weight-immaturity, birth asphyxia, sepsis and congenital malformation. ${ }^{7}$ and the most important cause of death within 24 hours is birth asphyxia. ${ }^{8}$ But the two most common causes of neonatal death, i.e. perinatal asphyxia and sepsis are $100 \%$ preventable, whereas the other two causes i.e. low birth weight and congenital anomalies are partially preventable.

In Assam neonatal mortality is very high (45.5/1000 live birth). ${ }^{9}$ In spite of the fact that birth asphyxia is the major killer of neonate in the first 24 hours, very few studies are available from this region regarding the causes of asphyxia. So we consider it important to identify antepartum, intrapartum and postnatal risk factors for neonatal mortality due to birth asphyxia and also to assess clinical and patho-biochemical status and outcome in the early neonatal period of babies who were asphyxiated at birth.

\section{MATERIAL AND METHODS}

A cohort study was conducted for a period of one year from $1^{\text {st }}$ August 2009 to $31^{\text {st }}$ July 2010 in the Neonatal Intensive Care Unit of Department of Paediatrics, Gauhati Medical College and Hospital, a Tertiary Care Hospital in North Eastern India. Ethical clearance from Hospital Ethical Committee was taken.

Total of one hundred and fifty cases of birth asphyxia babies who were admitted during this period were included.

\section{Inclusion Criteria}

1) Those with severe birth asphyxia (As per definition laid down by National Neonatology Forum of India, i.e. when a baby had gasping and inadequate breathing or no breathing at 1 minute after birth. It corresponds to 1 minute Apgar score of 3 or less as defined by NNF.10 2) Those with Apgar score of 5 at 5 minutes for inborn babies. 3) Out born babies without Apgar score but with poor or no cry from birth coupled with poor colour, respiratory distress, floppiness and loss of primitive reflexes.

\section{Exclusion Criteria}

1) Babies with Apgar score of at least 4 at 1 minute. 2) Those referred as birth asphyxia from outside, but no sign and symptoms of asphyxia. 3) Gestational age <34 weeks. 4) Newborns with major congenital malformations involving central nervous or cardiovascular system, dysmorphism (Obvious chromosomal abnormalities). 4) Severe hyperbilirubinemia.
5) Evidence of meningitis or bleeding disorders. 5) Those who are more than 15 days' old.

Enrolment was done within 12 hours of admission, after informed verbal consent from the mother or the attendant of each case. Detailed history was taken which included maternal age, working status, social status, past medical and obstetric history, parity, history of present pregnancy including hypertension, swelling of legs, fever, Antepartum Haemorrhage (APH), jaundice, convulsion, number of antenatal visits. Place and mode of delivery, conducting person, indication of Lower Segment Caesarean Section (LSCS) or instrumental delivery, duration of labour, Prolonged Rupture of Membrane (PROM), use of any drug, colour of liquor, babies condition at birth, need for any form of resuscitation and if resuscitation was required then up to which level.

Babies were examined regarding their weight, length, temperature, heart rate, respiratory rate, colour, fontanelles, systemic examination of cardiovascular, respiratory, abdomen and particularly nervous system in terms of muscle tone and primitive reflexes. Any evidence of birth injury or anomaly was also noted. Gestational age in completed weeks was assessed by an accurate menstrual history and each case was confirmed by New Ballard scoring. Babies were followed up twice daily. Course during hospitalization was noted with particular emphasis for presence of pallor, cyanosis, apnoea, respiratory distress, level of consciousness, convulsion, muscle tone, abdominal distension or GI bleeding.

Management was given according to the protocol of the unit which included management of intravenous fluid, injectable antibiotics and initial management of convulsion with phenobarbitone followed by phenytoin if seizure were not controlled by phenobarbitone. Inotropes were used as indicated. Other complications were addressed appropriately.

Investigations included $\mathrm{Hb} \%$, sepsis screen (Total leukocyte count, absolute neutrophil count, band cell neutrophil ratio and C-reactive protein), total platelet count, blood sugar, serum electrolyte, serum creatinine was done in all cases and prothrombin time was done when indicated.

\section{RESULTS}

Over the period of one year, all cases admitted with severe asphyxia were included in the study and no. of cases were found to be 150 . Out of 150 cases, female:male ratio was 1:2.3. Most of the asphyxiated babies admitted within 24 hours (84\%). Most of the neonates (52\%) were born outside this hospital, i.e. in local hospital from where it was referred home, primary health centre or on the way to hospital. Percentage of caesarean section deliveries was also lower (14.7\%). Most of the asphyxiated babies were term (96\%); 63\% asphyxiated babies were born to primi gravida mothers.

Among the identified risk factors poor antenatal check-up, anaemia, pregnancy-induced hypertension, eclampsia, antepartum haemorrhage, magnesium sulphate $\left(\mathrm{MgSO}_{4}\right)$ use during labour, prolonged labour, eclampsia, maternal diabetes, delivery outside hospital, meconium stained liquor and PROM were found significantly higher among the mothers (Table I).

A significant number of cases needed more than initial steps during resuscitation (47.4\%). Observed neonatal complications were Hypoxic Ischemic Encephalopathy (HIE) (24\% HIE I, 32\% HIE II, 44\% HIE III). 
Out of all cases, $60 \%$ subsequently developed seizure during the course of hospital stay for which $80 \%$ required one drug and other $20 \%$ required more than one drug; $32 \%$ cases required mechanical ventilation. Most of the cases had negative sepsis screening (99.3\%). Serum potassium was found to be raised in $78.7 \%$; $9.3 \%$ cases subsequently developed renal failure (serum creatinine level $>1.5 \mathrm{mg} / \mathrm{dL}$ ). Most of the cases required circulatory support (dopamine $45.3 \%$, dopamine and dobutamine in $9.3 \%$ ). Out of the total 150 babies, $48 \%$ expired and $43.3 \%$ discharged with some neurological sequelae.

\begin{tabular}{|c|c|c|}
\hline \multirow{2}{*}{ Factors } & \multicolumn{2}{|c|}{ Cases } \\
\cline { 2 - 3 } & No. & \% \\
\hline No or <3 antenatal visits & 72 & $48 \%$ \\
\hline Antenatal vaginal bleeding & 4 & $2.7 \%$ \\
\hline Fever within 2 weeks of delivery & 14 & $9.3 \%$ \\
\hline Anaemia & 117 & $78 \%$ \\
\hline Oedema & 31 & $20.7 \%$ \\
\hline Pregnancy induced hypertension & 31 & $20.7 \%$ \\
\hline Eclampsia & 23 & $15.3 \%$ \\
\hline Home delivery & 6 & $4 \%$ \\
\hline $\begin{array}{c}\text { Delivered outside GMCH } \\
\text { (But not at home) }\end{array}$ & 72 & $48 \%$ \\
\hline Delivered at GMCH & 72 & $48 \%$ \\
\hline Mode of delivery NVD & 126 & $84 \%$ \\
\hline Mode C-Section & 22 & $14.7 \%$ \\
\hline Meconium stained liquor & 58 & $38.7 \%$ \\
\hline $\begin{array}{c}\text { Prolonged rupture of } \\
\text { membrane }>18 \text { hours }\end{array}$ & 38 & $25.3 \%$ \\
\hline Presentation other than cephalic & 3 & $2 \%$ \\
\hline Antepartum foetal distress & 22 & $14.7 \%$ \\
\hline Prolonged labour & 42 & $28 \%$ \\
\hline Maternal diabetes mellitus & 1 & $0.7 \%$ \\
\hline Obstructed labour & 6 & $4 \%$ \\
\hline Cord around the neck & 6 & $4 \%$ \\
\hline Cephalo-pelvic disproportion & 2 & $1.3 \%$ \\
\hline Table I Risk Factors for Birth Asphyxia (n=150)
\end{tabular}

Table I: Risk Factors for Birth Asphyxia $(n=150)$

\section{DISCUSSION}

This study was done to find out the risk factors and short-term outcome of birth asphyxiated babies and there were limited studies in north eastern region and there was no published data from Assam. Definition of birth asphyxia was simplified for easy communication with illiterate people. Moreover, strict adherence to the ventilatory need or biochemical parameters for defining asphyxia by American Academy of Paediatrics (AAP) was not possible, because of limited laboratory support in our centre.

In this study, Female-to-male ratio was approximately 1:2.3. In a study by Shrestha $M$ et al 2006, found female-male ratio of 1:1.6.11 Rehana $M$ et al 2007 observed female-male ratio of $1: 1.5 .1248 \%$ of asphyxiated babies were inborn. Maternal age did not show any association with birth asphyxia, but parity was found to be an important factor; $63.3 \%$ of the asphyxiated babies were born to primi gravidae mothers. Study by Muhammad A et al also found similar result in his study (47\%). ${ }^{13}$ In primi gravida mother prolonged labour is usually common, which might be the cause of prolonged foetal hypoxia and neonatal asphyxia.

Incidence of caesarean section delivery in this study was $14.7 \%$ among the asphyxiated group mothers. This nearly approaches other studies like study by Rehana M, et al 2007, where $20 \%$ deliveries were done by caesarean section and study by $\mathrm{T}$ Shrestha et al 2006, where it was $20 \% .11,12$ This indicates that timely planned caesarean section in complicated cases could have saved many of these babies from being asphyxiated at birth.

Regarding intrapartum risk factors meconium stained liquor was the most frequently associated with asphyxia, which was seen in $38.7 \%$ asphyxiated babies. Similar study by David R Hall et al also found that among the asphyxiated babies, $47 \%$ had meconium stained liquor during labour. ${ }^{14}$ Prolonged rupture of membrane ( $>18 \mathrm{hrs}$.) plays a significant role in birth asphyxia as $27.8 \%$ of asphyxiated babies had prolonged rupture of membrane, similar to the study by Rehana M where it was found to be $24 \% .^{12}$

Among antenatal risk factors, it was found that there was a poor antenatal visit. Among asphyxiated babies, $48 \%$ mothers had inadequate antenatal visits. Study by Rehana $M$ et al reported $64 \%$ of cases had no antenatal checkup. ${ }^{12}$ Muhammad A et al reported similar finding with 39\% cases had history of no antenatal checkup. ${ }^{13}$ This reflect the low awareness and importance for proper antenatal check-up in our society, which delay the prediction and detection of pregnancy induced complication and its proper intervention on time.

In this study, other important maternal risk factors that were encountered more frequently among the asphyxiated babies were maternal anaemia (78\%), prolonged labour (28\%), pregnancy induced hypertension (20.7\%), eclampsia (15.3\%), obstructed labour (4\%), antepartum foetal distress $(14.7 \%)$ and cord around the neck (4\%). Muhammad A et al 2004 reported similar finding with pregnancy induced hypertension (20\%), eclampsia (16\%) and obstructed labour (5\%). ${ }^{13}$ Study by Rehana $M$ et al reported similar finding like maternal anaemia $(60 \%)$ and pregnancy induced hypertension (19.2\%).12 Regarding factor like cord around the neck, study by Kumari $\mathrm{S}$ et al reported $4.2 \%$ cases of deliveries were associated cord accident. ${ }^{15}$ Maternal anaemia is found to be great risk for asphyxia, probably because of placental insufficiency during the antenatal period followed by intrapartum hypoxia during delivery.

In this study, $91.3 \%$ asphyxiated babies were admitted with unable to feed, $41.3 \%$ with cyanosis, $96 \%$ with lethargy, $4 \%$ with irritability, $22 \%$ with convulsion, $32 \%$ with respiratory distress, $98 \%$ with decreased tone and $2 \%$ with increased tone at the time of admission. Study by Rehana M, et al reported $40 \%$ asphyxiated babies were admitted with unable to feed, $56 \%$ with poor feeding, $42 \%$ with cyanosis, $52 \%$ with lethargy, $36 \%$ with irritability, $28 \%$ with convulsion, $46 \%$ with respiratory distress, $44 \%$ with decreased tone and $25 \%$ with increased tone at the time of admission. ${ }^{12}$

The complications observed in the present study were HIE (24\% in stage I, $32 \%$ in stage II and $44 \%$ in stage III), convulsion (60\%), cardiogenic shock needing inotropic support (55.3\%), multi-organ involvement (renal failure in $9.3 \%$, disseminated intravascular coagulation $0.7 \%$ ). Muhammad A et al reported similar incidence of HIE I, II and III were $39 \%, 55 \%$ and $06 \%$ respectively. ${ }^{13}$ Rehana $\mathrm{M}$ et al reported incidence of HIE I, II and III were $36 \%, 20 \%$ and $8 \%$ respectively. ${ }^{12}$

Mechanical ventilation in neonates has improvised the outcome of sick new born and it is the single most important advancement in neonatal medicine, which has reduced 
neonatal mortality. ${ }^{16}$ In our study, $41.3 \%$ asphyxiated babies subsequently developed respiratory failure for which they needed ventilatory support.

In this study, mortality rate was found to be $48 \%$. Similar observations were reported by Mullingan JC et al and Chowdhury $\mathrm{M}$ et al, who found morality of $44 \%$ and $40 \%$ respectively due to birth asphyxia. ${ }^{17,18}$ It was seen that the mortality was enhanced by severity of HIE. Most serious complications were seen with development of advance stage of HIE (Stage II and III) among asphyxiated babies. Mulligan JC et al also found similar results. ${ }^{17}$

In our study, $43.3 \%$ cases were discharged with some neurological sequelae, which was found to be the most devastating complication of birth asphyxia, because it creates tremendous psychosocial and economic burden not only to the family but also to the whole society.

Our study shows that a good number of antenatal factors may play a role in causation of cascade of events, which leads to birth asphyxia. A large number of cases had significant antenatal history, so both antenatal and intranatal factors can be taken as responsible for development of birth asphyxia. In our study, it is obvious that mode of delivery plays an important role and it signifies an inverse association between elective caesarean section and neonatal encephalopathy. ${ }^{19}$

\section{CONCLUSION}

This study found birth asphyxia was more common in term babies than preterm babies and among primi mothers. Most of the identified maternal risk factors include poor antenatal check-up, prolonged rupture of membrane, maternal anaemia, meconium stained liquor, fever within 2 weeks of delivery, pregnancy induced complication like hypertension, prolonged labour and cord around the neck were significantly related to asphyxia, as these factors can be prevented by proper antenatal check-up and proper monitoring during labour.

Among the serious neonatal complications, HIE was commonest in term asphyxiated neonates and mortality was higher in neonates with HIE.

It could be possible to reduce the occurrence of asphyxia and its complications by improving antenatal, intrapartum and neonatal care services within our limited resources.

\section{REFERENCES}

1. Fisher DL, Fraser BJ. School climate: assessing and improving school environments, Set. New Zealand Council for Educational Research 1990;2:1-8.

2. McIntosh N. The newborn. In: McIntosh N, Helms PJ, Smyth LR, eds. Forfar \& Arneil's textbook of paediatrics. Newyork: Churchill Livingstone 2008; $7^{\text {th }}$ edn:177-392.
3. González de Dios J, Moya M. Perinatal asphyxia, hypoxicischemic encephalopathy and neurological sequelae in full-term newborns. II. Description and interrelation. Rev Neurol 1996;24(132):969-76.

4. State of the world's children. UNICEF 2009.

5. The World health report: 2005: make every mother and child count. Report of the director General WHO 2005.

6. Kounteya Sinha. $70 \%$ of infant deaths within 30 days of birth, The Times of India Apr 3, 2012. Available at: http://timesofindia.indiatimes.com/india/70-of-infantdeaths-within-30-days-ofbirth/articleshow/12511990. cms,

7. Park K. Preventive medicine in obstetrics, paediatrics and geriatrics. Textbook of preventive \& social medicine, Jabalpur India: Banarsidas Bhanot 2011;21st edn:p 524.

8. Lee AC, Mullany LC, Tielsch JM, et al. Risk factors for neonatal mortality due to birth asphyxia in southern nepal: a prospective, community-based cohort study. Paediatrics 2008;121(5);e1381-e1390.

9. Infant and child mortality. National family health survey (NFHS-3) 2005-06. 2007; vol 1:p 187.

10. Report of the national neonatal perinatal satabase (National Neonatology Forum, India) 2000.

11. Shrestha M, Shrestha L, Shrestha PS. Profile of asphyxiated babies at tribhuvan university teaching hospital. J Nepal Paediatr Soc 2009:29(1):3-5.

12. Rehana M, Yasmeen M, Farrukh M, et al. Risk factors of birth asphyxia. J Ayub Med Coll Abbottabad 2007;19(3):67-71.

13. Azam Muhammad, Khan Pervaiz A, Malik FA. Birth asphyxia: risk factors. The Professional 2004;11(4):41623.

14. Hall DR, Smith M, Smith J. Maternal factors contributing to asphyxia neonatorum. Journal of Tropical Paediatrics 1996;42(4):192-5.

15. Kumari S, Sharma M, Yadav M, et al. Trends in neonatal outcome with low Apgar scores. Indian J Paediatr 1993;60(3):415-22.

16. Chowdhury MAKA. Institution of neonatal health of Bangladesh. Key Note speech. 1 ${ }^{\text {st }}$ National conference and scientific session, Bangladesh Neonatal Forum. $7^{\text {th }}$ Dec, 1999;p 23

17. Mulligan JC, Painter MJ, O’ Donoghue PA, et al. Neonatal asphyxia: neonatal mortality and long term sequelae. The Journal of Paediatrics 1980;96(5):903-07.

18. Chowdhury MAKA, Banu K, Rahman A. Birth asphyxia-a prospective study in Dhaka Shishu hospital. DS (Child) H J 1996;125:18-22.

19. Khreisa WH, Habahbeh Z. Risk factors of birth asphyxia: a study at Prince Ali Ben Al Hussein hospital Jordon. Pak J Med Sci 2005;21(1):30-4. 